\title{
Determination of Direct Tensile Strength Values of Rock Materials by a New Test Method of Drilled Disc Tension
}

\author{
Eren Komurlu*, Serhat Demir² \\ ${ }^{1}$ Department of Civil Engineering, Faculty of Engineering, Giresun University, 28100, Giresun, Turkey \\ 2 Department of Civil Engineering, Faculty of Engineering, Karadeniz Technical University, 61080, Trabzon, Turkey \\ * Corresponding author, e-mail: ekomurlu@giresun.edu.tr
}

Received: 19 September 2019, Accepted: 15 November 2019, Published online: 16 December 2019

\begin{abstract}
Use of drilled disc specimens was investigated with both numerical and experimental studies to determine direct tensile strengths of rock materials. A new loading apparatus with rods to insert into the drill holes of discs has been designed and manufactured to supply tension by using the compression test presses. In addition to the use of popular compressive presses for direct tension, elimination of the gluing in the standard direct tensile strength test method is a significant advantage to make possible both hard and soft rocks to be tested. The Brazilian test discs with the diameter of NX size and length to diameter ratio of 0.5 were used in tests. Different loading apparatus designs were analyzed and ideal angle of contact between rock and the loading rods was assessed to be $50^{\circ}$ within various choices investigated in this study. The drilled discs were determined to fail due to the crack initiation under the condition of uniaxial tensile stress distribution at sidewalls of the hole. In addition to the drilled disc tension test, standard direct tensile strength tests were also carried out to take as reference and compare the results obtained from different methods. According to the results of both numerical and experimental studies, an equation was suggested to determine uniaxial tensile strengths of drilled disc specimens with $20 \mathrm{~mm}$ hole diameter and the contact angle of $50^{\circ}$.
\end{abstract}

\section{Keywords}

Direct Tensile Strength tests (DTS), tensile strengths of rock materials, Finite Element Modelling, rock mechanics laboratory tests

\section{Introduction}

Tensile strength values of rock materials have a great importance for numerous topics in rock engineering. To determine tensile strength values of rock materials, various direct and indirect test methods have been proposed by different standards and researchers. The conventional Direct Tensile Strength (DTS) test has an important disadvantage of possible adhesive part failure instead of that in the rock specimen. The invalid failure of adhesive part can be seen especially for high strength rock materials. Besides of the use of adhesives for loading core specimens, different DTS test methods like using dog-bone shaped rock specimens have been developed for effective holding, but they are not popular because of impractical specimen preparation works [1-4].

To eliminate the lacks of standard (conventional) direct tensile strength test, various indirect tests were developed. The Brazilian test (or splitting tensile strength test) is the most popular one in the Indirect Tensile Strength (ITS) tests because of its practicality. Although the Brazilian test is applied worldwide, its deficiencies cannot be ignored and have been an important issue to investigate by the community on rock testing [5-8].

Because the Brazilian test discs fail under biaxial stress distribution condition, it has a notable problem and cannot be used to evaluate the uniaxial tensile strength values of rock materials [9-12]. The Brazilian test has another problem resulting from indefinite contact conditions. The contact properties like contact angle and frictions significantly change the stress distribution in discs depending on deformation characteristics of rock materials. ITS values obtained from the Brazilian test are not only dependent on the strength of the disc specimen material, but also dependent on deformability properties [13-15].

High compressive stress regions in the Brazilian discs are located just beneath the contact points of the loading jaw. Due to the possibility of crack initiation in the comp- 
ression zone beneath the contact points, determination of the ITS values of rock materials under the diametric compression is disadvantageous [16-18].

Various reasons as written above indicate the importance of Direct Tensile Strength (DTS) test methods. In this study, a new direct tensile strength test method of using drilled Brazilian test disc specimens was investigated by both experimental and numerical analyses. The Brazilian test discs were drilled and used in a new direct tensile strength test investigated within this study. The motivation for carrying out this study is having an ability to determine DTS values by using a compression test press which is a very widely used equipment in rock mechanics laboratories. Additionally, using no adhesive to hold and load specimens was assessed to be another significant advantage.

To supply tension in the hole of discs by using the compression test press, a new apparatus has been designed and manufactured as seen in Fig. 1. To make tension, the devices of the Drilled Disc Tension (DDT) apparatus displaced in oppose to the press movement. As the compression of the press continues, the tensile stress increases until the failure.

In this study, the failure mechanism of drilled Brazilian discs were investigated to assess whether the new DDT apparatus can be used to determine the uniaxial tensile strength values of rock materials. The ideal failure shape for a valid test, stress distribution in the critical locations for the crack initiation were investigated carrying out three dimensional numerical modelling. In addition, a series of experimental analyses was carried out to check results obtained from the numerical analyses. In the experimental study, both conventional direct tensile strength test and the DDT test were performed to determine the relation between results of the standard and new test methods.

\section{Materials and methods}

\subsection{Numerical study}

To better understand the stress distributions around drill holes with different contact angles, Finite Element Analyses (FEA) were performed by using the ANSYS software which contain special elements and material models for brittle materials like rocks. In the numerical study, failure of the models was investigated to assess whether it is valid under the control of the uniaxial tensile stress concentration.

As parallel to the suggestions of International Society for Rock Mechanics and Rock Engineering (ISRM), the Brazilian disc models were modelled to have the diameter of NX size $(54 \mathrm{~mm})$ and length to diameter ratio of 0.5 [19]. Material properties as input values for the rock models are given in Table 1. Different materials were modelled in the analyses to investigate whether a hole drilling and tool contact design has same effect in case of having different material properties like Poisson's ratio and modulus of elasticity. Material of the loading apparatus was modeled with Solid185 as rigid steel with 350 GPa modulus of elasticity. The contact surfaces between the rock and loading apparatus were simulated with the Conta174 and Targe170 contact pairs. Different coefficient of friction values of 0.3 and 0.6 were used to investigate the effect of the friction between rock and steel of the loading apparatus on the results of the analyses.

Considering the drill process practicality and having enough area for insertion of the tension apparatus rods, drill hole diameter of $20 \mathrm{~mm}$ was investigated within both numerical and experimental studies. In case of relatively small drill hole diameters, rod dimensions should be decreased to be inserted and can be not sufficient to supply enough load bearing capacity for the rock specimen failure. For having a definite contact angle, the rods were modelled to have same diameter with that of the holes.

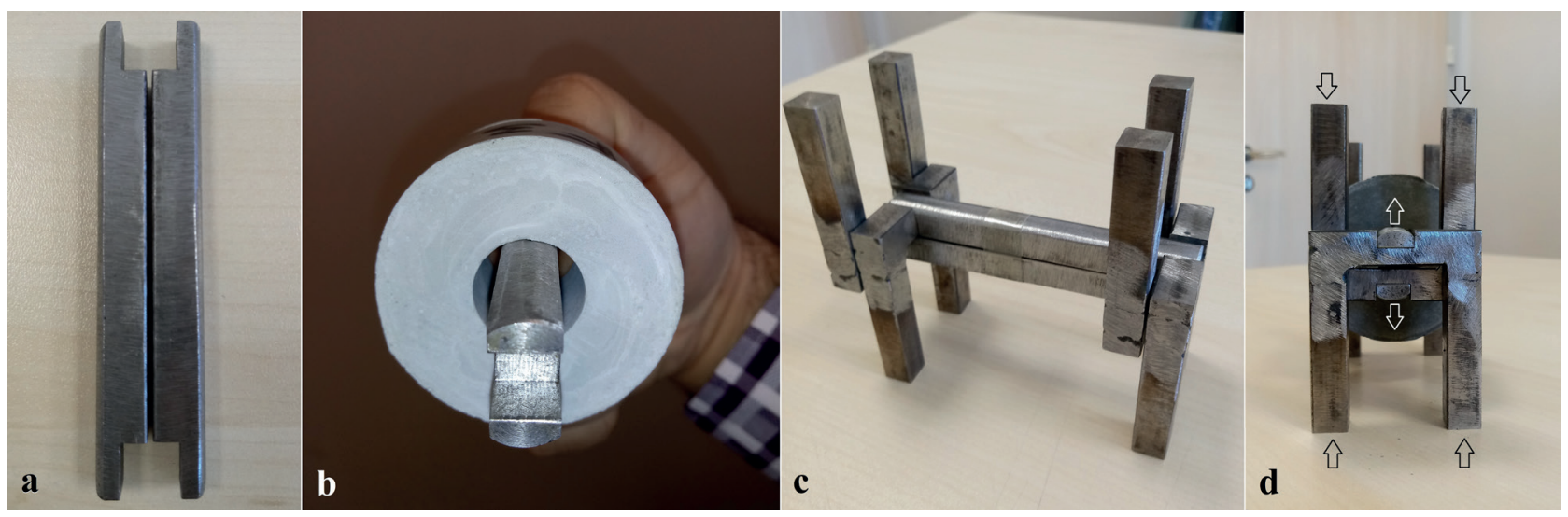

Fig. 1 a) Loding rods, b) rods inserted disc, c) and d) DDT test apparatus 
Table 1 Material Properties of rock models

(L: Low, H: High, E: Modulus of elasticity, v: Poisson's ratio)

\begin{tabular}{lcccc}
\hline Model & $\mathrm{E}(\mathrm{GPa})$ & $\mathrm{v}$ & $\sigma_{\mathrm{c}}(\mathrm{MPa})$ & $\sigma_{\mathrm{t}}(\mathrm{MPa})$ \\
\hline Material 1 (LE-Lv) & 20 & 0.2 & 50 & 5 \\
Material 2 (HE-Lv) & 40 & 0.2 & 50 & 5 \\
Material 3 (LE-Hv) & 20 & 0.4 & 50 & 5 \\
Material 4 (HE-Hv) & 40 & 0.4 & 50 & 5 \\
\hline
\end{tabular}

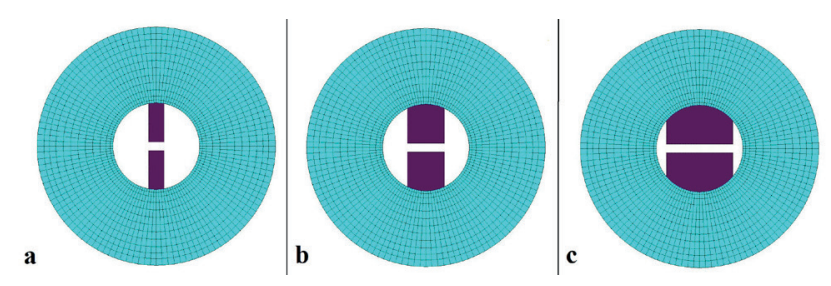

Fig. 2 Drilled disc models with different contact angles of a) $20^{\circ}$, b) $50^{\circ}$ and c) $100^{\circ}$

As seen in Fig. 2, different contact angles of rod and drill hole surfaces of $20^{\circ}, 50^{\circ}$ and $100^{\circ}$ were modelled within the numerical analyses to investigate the contact angle effect on stress distributions in drilled discs and the strength test results.

Eight-node solid brick elements (Solid65) were used for three-dimensional modelling of rocks, which have the capability of cracking in tension, crushing in compression, plastic deformation, and three degrees of freedom at each node, including transition in the nodal $\mathrm{x}, \mathrm{y}$, and $\mathrm{z}$ directions. It is stated in the ANSYS software manuals that the Solid 65 elements are usable to simulate failure in brittle geological materials such as rocks. More details about Solid65 can be found in section 14.65 of the ANSYS Theory Reference [20].

Materials were modelled by considering the linear and non-linear properties defining the behaviors of the elements. The modelled material was defined as linear elastic material until the crack initiation occurs. After the crack initiation, change of the normal and shear stresses has been re-calculated by the program. The re-calculated shear stresses were transferred by the plasticity due to the generated open and closed cracks. The shear transfer coefficient was accepted as 0.3 and 0.1 for closed and open cracks, respectively. In addition, the stiffness reduction factor considered as 0.6 to define plasticity had an important role in the behavior of cracked elements. These models predicted the failure of brittle materials according to the WillamWarnke failure criteria used for concrete, rocks and other cohesive-frictional materials such as ceramics [21].

Static analyses were performed for each of the models by using an implicit solver in ANSYS, and the full Newton-Raphson method was used for non-linear analysis.
For displacement-controlled loading, displacements were divided into multiple sub-steps until the total displacement was achieved. Stress distributions and cracking mechanisms for all specimen models were plotted for comparison with the experimental results.

The mesh length in the rock models was chosen to be $0.4 \mathrm{~mm}$ around drill holes where is the most critical part for the start of failure and increase from $0.4 \mathrm{~mm}$ depending on the distance from the hole. Various finite element models with different meshes were analyzed in an effort to ensure that the selected mesh is dense enough to provide sufficient solution convergence. A figure for the meshing condition is given in Fig. 2. In this numerical analysis, the DDT test was simulated applying load from up and down side parallel rods of the apparatus, in opposite directions.

\subsection{Experimental study}

To check findings from the numerical study, both DDT and standard Direct Tensile Strength (DTS) tests were performed by using homogeneous and isotropic rocklike materials in this study. The tensile strength values of DDT test specimens were compared with those obtained from the standard test method. The rods of the loading apparatus used in the DDT test was inserted into the holes and stands of the rods were mounted later on. The up-side and down-side rods were respectively moved upward and downward as the hydraulic press pushes the stands in the opposite directions (Fig. 1 (d)).

To make a homogeneous and isotropic rocklike material, only Cem I type ordinary Portland cement and tap water were used. The mix had the ratio of water to cement of 0.5 by weight. The mix was homogenized in a concrete mixer for 10 minutes. Then, the specimens were casted into NX size diameter molds with the bottom allowing the bleed water drainage, compacted using tamping rods, and put on the vibration table to remove air in fresh mix. The standard test specimens were casted into the molds with the NX size diameters and the ratio of length to diameter of 3 in two steps for making them well compacted and removing air in the mix properly by using tamping rods after each casting steps.

DDT and standard tensile strength tests were performed to determine the DTS values of the cementitious rocklike specimens with different curing times of 2 and 28 days. According to ISRM suggestions, all of the standard test specimens had same length to diameter ratio of 3 . In the DDT test, discs had the length to diameter ratio of 0.5 , which is the ratio suggested for the Brazilian discs [19]. 
The DTT test specimens were prepared in two different ways to make holes. In a way, solid steel cylinders with the diameter of $20 \mathrm{~mm}$ were put in the molds before casting the cementitious mix. To make holes at the middle, the centers of the circular cross-sections of the cylinders and molds were carefully put on the same line in vertical with sensitive measurements. The steel cylinders were lubricated before the casting step and removed by gently pulling out from the specimens at the curing time of a day. In the other and second way, the holes of discs were made by using a driller machine (Fig. 3). By the way of making holes with two different ways, the effect of the driller machine process could be investigated to assess whether it causes a damage decreasing strength values of the disc specimens, or not.

Using a strong epoxy based adhesive, standard DTS test specimens were glued to the steel caps which had been manufactured to be held by the grips of tension test equipment (Fig. 4 (a)). As parallel to the ISRM suggestion, the loading rate was chosen to be $0.2 \mathrm{kN} / \mathrm{sec}$ for both standard and DDT test specimens.

\section{Results}

The numerical modelling study results are given in Tables 2-6. Stress distributions at the sidewalls where is the crack initiation location are given for different contact

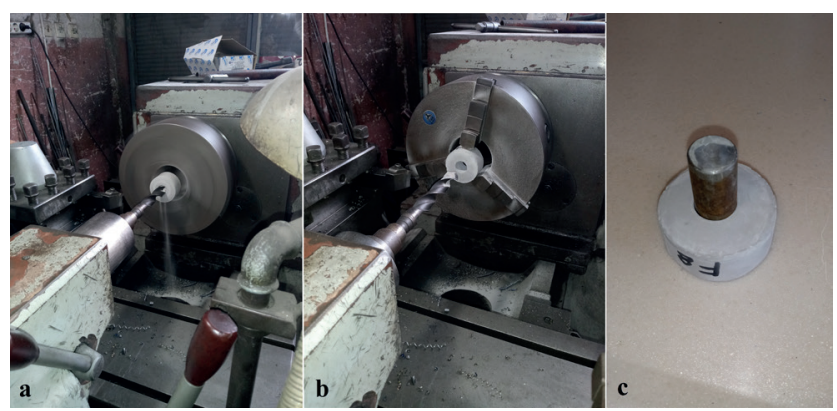

Fig. 3 a) drilling hole, b) a drilled disc, c) a casted disc with hole

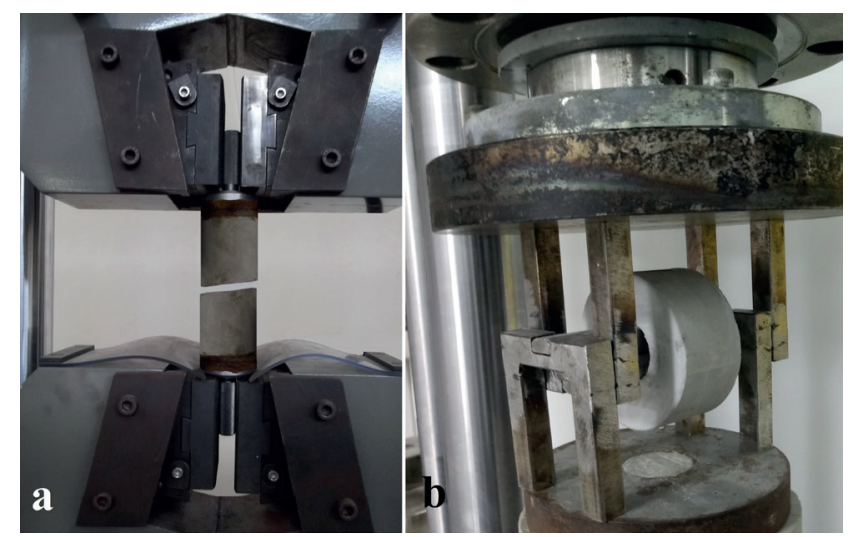

Fig. 4 a) Standard direct tensile strength test, b) DDT test angles in Table 2. The maximum tensile and compressive stresses were determined to induce at the sidewalls and the contact surface of the hole, respectively. As seen in Table 3, compressive stress concentration increases with a decrease in the contact angle. To eliminate invalid failures resulting from the compressive stresses at the contact zone, it was inferred that small contact angles should not be used. As another important finding, the compressive stresses at the contact zone was determined to increase with increasing modulus of elasticity values (Table 4). For the aim of eliminating the invalid compressive failure, the contact angles of $50^{\circ}$ and $100^{\circ}$ were found to be more advantageous in comparison with the case of using the contact angle of $20^{\circ}$. On the other hand, intermediate and minor principle stresses at the sidewalls increase with an increase in the contact angle. Therefore, it should be noted that stress distributions become more deviated from the uniaxial stress condition as the contact angle increases. When considered this point of view, further analyses for different rock material models were carried out for the contact angle of $50^{\circ}$. There was lower than $4 \%$ deviation between the major principle stress at the sidewalls and the uniaxial tensile strength value of the models with the contact angle of $50^{\circ}$ (Table 5). The maximum loads obtained from different material models and the relation between failure load and the uniaxial tensile strength values of different models are given in Tables 5 and 6, respectively. Typical stress distributions in the DDT test specimen models are given in Fig. 5.

As parallel with the findings from the numerical analyses, cracks occurred at the sidewalls of the holes and specimens were divided into two from the diameter of the discs in the experimental study (Fig. 6). The DDT test results obtained under the case of the contact angle of $50^{\circ}$ are given in Table 7. The standard direct tensile strength test results in Table 8 were considered to examine the results obtained from the DDT test. The Uniaxial Tensile Strength (UTS) values of specimens were calculated as the ratio of the failure load to the circular cross-section area of the standard DTS test specimens. The relation between DDT test and the standard Uniaxial Tensile Strength (UTS) test results are seen in Table 9.

According to the results of both numerical and experimental studies, Eq. (1) was found to be usable for determination of the uniaxial tensile strength values of the DDT test specimens with the relevant diameter sizes and lengths of both disc and the hole. 
Table 2 Failure loads and stress distribution in rock models at the sidewalls, maximum tension location (Material 1, Coefficient of friction between rock and rod: 0.3, -: Compression)

\begin{tabular}{lcccc}
\hline Contact angle & $\begin{array}{c}\text { Failure Loads } \\
(\mathrm{kN})\end{array}$ & Max. tension location & $\begin{array}{c}\text { Major principal stress } \\
(\mathrm{MPa}), \sigma_{1}\left(\sigma_{\mathrm{y}}\right)\end{array}$ & $\begin{array}{c}\text { Intermediate principal stress } \\
(\mathrm{MPa}), \sigma_{2}\left(\sigma_{\mathrm{x}}\right)\end{array}$ \\
\hline $20^{\circ}$ & 1.174 & Sidewalls & 5.17 & 0.33 \\
$50^{\circ}$ & 1.201 & Sidewalls & 5.16 & -0.08 \\
$100^{\circ}$ & 1.265 & Sidewalls & 5.17 & -0.35 \\
\hline
\end{tabular}

Table 3 Maximum compressive stresses $\left(\sigma_{\text {cmax }}\right)$ induced under different contact angle conditions for Material 1 (Coefficient of friction between rock and rod: $0.3, \sigma_{\operatorname{tmax}}$ : Maximum tensile stress (the major principal stress at the sidewall))

\begin{tabular}{lccc}
\hline Contact angle & Maximum compressive Stress $(\mathrm{MPa}), \sigma_{\mathrm{cmax}}$ & Maximum compression location & $\sigma_{\mathrm{cmax}} / \sigma_{\mathrm{tmax}}$ \\
\hline $20^{\circ}$ & 13.74 & Contact zone & 2.66 \\
$50^{\circ}$ & 8.51 & Contact zone & 1.65 \\
$100^{\circ}$ & 4.19 & Contact zone & 0.81 \\
\hline
\end{tabular}

Table 4 Maximum compressive stresses induced in different models with the contact angle of $50^{\circ}$ (CF: Coefficient of friction)

\begin{tabular}{lccc}
\hline Model name & Maximum compressive Stress (MPa), $\sigma_{\text {cmax }}$ & Max. compression location & $\sigma_{\mathrm{cmax}} / \sigma_{\mathrm{tmax}}$ \\
\hline Material 1 (CF: 0.3) & 8.51 & Contact zone & 1.65 \\
Material 2 (CF: 0.3) & 12.19 & Contact zone & 2.36 \\
Material 3 (CF: 0.3$)$ & 8.58 & Contact zone & 1.66 \\
Material 4 (CF: 0.3$)$ & 12.15 & Contact zone & 2.35 \\
Material 1 (CF: 0.6$)$ & 8.51 & Contact zone & 1.65 \\
Material 2 (CF: 0.6$)$ & 12.17 & Contact zone & 2.36 \\
Material 3 (CF: 0.6$)$ & 8.56 & Contact zone & 1.65 \\
Material 4 (CF: 0.6$)$ & 12.14 & Contact zone & 2.35 \\
\hline
\end{tabular}

Table 5 Failure loads and tensile stress distribution at the maximum tension location of different rock material models (-: Compression)

\begin{tabular}{|c|c|c|c|c|c|}
\hline Model name & Failure Loads (kN) & Max. tension location & $\begin{array}{l}\text { Major principal stress } \\
(\mathrm{MPa}), \sigma_{1}\left(\sigma_{\mathrm{y}}\right)\end{array}$ & $\begin{array}{c}\text { Intermediate principal } \\
\text { stress }(\mathrm{MPa}), \sigma_{2}\left(\sigma_{\mathrm{x}}\right)\end{array}$ & $\begin{array}{c}\text { Minor principal stress } \\
(\mathrm{MPa}), \sigma_{3}\left(\sigma_{\mathrm{z}}\right)\end{array}$ \\
\hline Material 1 (CF: 0.3) & 1.201 & Sidewalls & 5.16 & 0.35 & -0.13 \\
\hline Material 2 (CF: 0.3) & 1.195 & Sidewalls & 5.16 & 0.39 & -0.18 \\
\hline Material 3 (CF: 0.3) & 1.160 & Sidewalls & 5.18 & 0.44 & -0.20 \\
\hline Material 4 (CF: 0.3) & 1.164 & Sidewalls & 5.17 & 0.32 & -0.11 \\
\hline Material 1 (CF: 0.6) & 1.198 & Sidewalls & 5.16 & 0.38 & -0.19 \\
\hline Material 2 (CF: 0.6) & 1.193 & Sidewalls & 5.15 & 0.27 & -0.10 \\
\hline Material 3 (CF: 0.6) & 1.159 & Sidewalls & 5.18 & 0.36 & -0.12 \\
\hline Material 4 (CF: 0.6) & 1.152 & Sidewalls & 5.17 & 0.40 & -0.17 \\
\hline
\end{tabular}

Table 6 Relation between failure loads and tensile strength values of different models with the contact angle of $50^{\circ}$

\begin{tabular}{cccc}
\hline Model name & Failure Loads $(\mathrm{kN})$ & $\mathrm{UTS}(\mathrm{MPa})$ & Equation \\
\hline Material 1 (CF: 0.3) & 1.201 & 5 & $\mathrm{UTS}=0.416 \mathrm{~F}_{\max } / \mathrm{cm}^{2}$ \\
Material 2 (CF: 0.3) & 1.195 & 5 & $\mathrm{UTS}=0.418 \mathrm{~F}_{\max } / \mathrm{cm}^{2}$ \\
Material 3 (CF: 0.3) & 1.160 & 5 & $\mathrm{UTS}=0.431 \mathrm{~F}_{\max } / \mathrm{cm}^{2}$ \\
Material 4 (CF: 0.3) & 1.164 & 5 & $\mathrm{UTS}=0.430 \mathrm{~F}_{\max } / \mathrm{cm}^{2}$ \\
Material 1 (CF: 0.6) & 1.198 & 5 & $\mathrm{UTS}=0.417 \mathrm{~F}_{\text {max }} / \mathrm{cm}^{2}$ \\
Material 2 (CF: 0.6) & 1.193 & 5 & $\mathrm{UTS}=0.419 \mathrm{~F}_{\max } / \mathrm{cm}^{2}$ \\
Material 3 (CF: 0.6) & 1.159 & 5 & $\mathrm{UTS}=0.431 \mathrm{~F}_{\max } / \mathrm{cm}^{2}$ \\
Material 4 (CF: 0.6) & 1.152 & $\mathrm{UTS}=0.434 \mathrm{~F}_{\max } / \mathrm{cm}^{2}$ \\
\hline
\end{tabular}




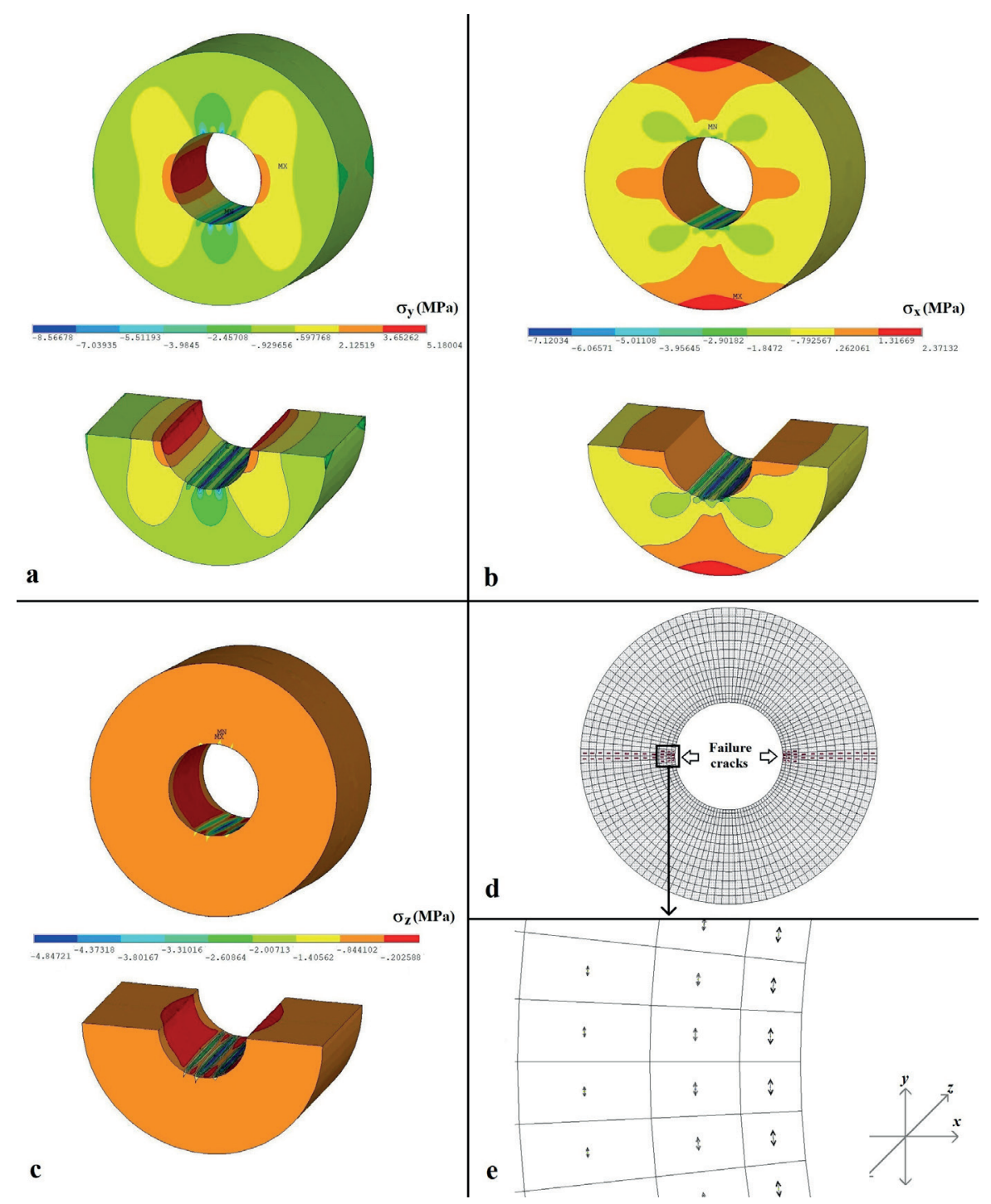

Fig. 5 Stress distribution of a drilled disc model with the contact angle of $50^{\circ}$ in a) y, b) $x$, c) z d) directions, failure cracks and e) principal stress vectors at the sidewalls (Material 3, CF: 0.3)

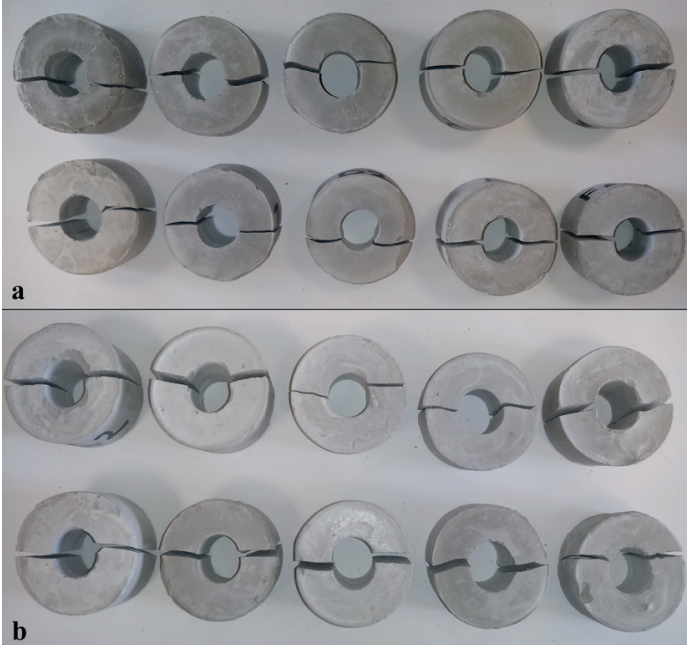

Fig. 6 a) Failure of discs with drilled holes, b) failure of discs with holes made by casting

$$
U T S=0.4 F_{\max } / \mathrm{cm}^{2},
$$

where $F_{\text {max }}$ is the failure load in the DDT test and UTS is the uniaxial tensile strength. It should be reminded herein that the Eq. (1) is valid for the discs with the diameter of NX size and length to diameter ratio of 0.5 . Additionally, hole diameter must be $20 \mathrm{~mm}$ for using Eq. (1) to calculate the UTS value.

\section{Discussions}

The new tensile strength evaluation method of DDT test was found to supply a significant advantage because of eliminating the adhesive failure problem. The DDT test specimens were found to be able to prepare by an easy drilling work. It should be noted herein that the hole with the diameter of $20 \mathrm{~mm}$ was practical to be made in one-step 
Table 7 Experimental study results of DDT test (S.N.: Specimen number, S.D.: Standard deviation)

\begin{tabular}{lccc}
\hline Specimen & Failure Load $(\mathrm{N})$ & S.N. & S.D $(\mathrm{N})$ \\
\hline 2 days cured, Drilled & 453 & 5 & 19 \\
2 days cured, Casted & 447 & 5 & 22 \\
28 days cured, Drilled & 938 & 5 & 25 \\
28 days cured, Casted & 950 & 5 & 27 \\
\hline
\end{tabular}

Table 8 Standard uniaxial tensile strength test results

\begin{tabular}{lccc}
\hline Specimen & UTS $(\mathrm{MPa})$ & Specimen number & S.D (MPa) \\
\hline 2 days cured & 1.79 & 4 & 0.11 \\
28 days cured & 3.84 & 4 & 0.16 \\
\hline
\end{tabular}

Table 9 Relation between failure load of DDT test specimens and uniaxial tensile strength values

\begin{tabular}{lc}
\hline Specimen & Equation \\
\hline 2 days, Drilled & $\mathrm{UTS}=0.395 \mathrm{~F}_{\max } / \mathrm{cm}^{2}$ \\
2 days, Casted & $\mathrm{UTS}=0.400 \mathrm{~F}_{\max } / \mathrm{cm}^{2}$ \\
28 days, Drilled & $\mathrm{UTS}=0.409 \mathrm{~F}_{\max } / \mathrm{cm}^{2}$ \\
28 days, Casted & $\mathrm{UTS}=0.404 \mathrm{~F}_{\max } / \mathrm{cm}^{2}$ \\
\hline
\end{tabular}

drilling. In case of preparing hard and brittle rocks, more than one drilling steps with increasing bit diameters can be applied to prevent rock cracking. On this topic, new studies will guide for development of the DDT test specimen preparation details.

According to the results obtained from both numerical and experimental studies, use of Eq. (1) is suggested for determination of the DTS values of rock materials in the case of $20 \mathrm{~mm}$ drill diameter, NX size disc diameter and specimen length to diameter ratio of 0.5 . Since stress distribution in the drilled disc specimens can vary with the change of geometry and size parameters, the findings of this study should be considered for only the relevant case written above [22-24].

The hole drilling location is also an important point for a valid test to use Eq. (1). The hole should be drilled at the middle of the circular cross-section of the rock discs and through the specimen length without a deviation [25].

Ideal tension cracking was determined to propagate along the horizontal diameter of the disc specimens. In case of having no ideal cracking at the sidewalls, the location of the maximum tensile stress concentration, the test can not be considered as valid. For instance, in homogeneities can sometimes cause unexpected failure shapes [26, 27].

Compressive strength values of rock materials are generally 8 or more times higher than their tensile strength values [28-30]. The compressive stresses at the contact of the hole and the loading apparatus steel were found to be not enough high to cause an invalid failure in case of the contact angle of $50^{\circ}$. The maximum compressive stresses induced at the contact location was about 2-3 times of the maximum tensile stress level at the sidewalls of the hole. Therefore, $50^{\circ}$ was assessed to be a proper contact angle in terms of eliminating the compressive failure. As an important finding from the numerical study, the compressive stress concentration at the contact was determined to significantly increase with an increase in the modulus of elasticity values of rock materials (Table 4). Use of rods with small contact angles like $20^{\circ}$ or lower ones can make invalid failure in case of testing rigid rock specimens. Fortunately, it is easy to designate the compressive invalid failure from the cracking location.

There is three dimensional stress distribution at sidewalls of drill holes which are the location of the maximum tensile stresses induced. The major principal stress at sidewalls is tensile stress in vertical which is parallel to the loading direction. Additionally, two horizontal stresses which are parallel and perpendicular to drill-hole direction are minor and intermediate principal stresses at sidewalls. Because the intermediate and minor stresses are respectively tensile and compressive stresses and have low values at the sidewalls, stress distribution can be practically considered as uniaxial for the location of the maximum tension. It is advantageous to have low level minor and intermediate principal stresses that can make the major principal stress values to be quite close to the uniaxial tensile strength value $[31,32]$.

Because the intermediate stress level was found to increase with an increase in the contact angle, the contact angle of $50^{\circ}$ was assessed to be more proper than $100^{\circ}$ (Table 2). Within different contact angles analyzed in the numerical study, the contact angle of $50^{\circ}$ was found to be the ideal choice. Therefore, contact angle of the loading apparatus was selected as $50^{\circ}$ in the experimental study. By the way, it is necessary to state that Eq. (1) is valid for the use of loading apparatus with the contact angle of $50^{\circ}$.

In spite of the variations in the modulus of elasticity and Poisson's ratio, failure loads and major principal stresses at sidewalls were determined to be similar because of small values of intermediate and minor principal stresses in horizontal direction.

Because of the low horizontal stresses at the critical part of the maximum tension in vertical direction, the material properties effect on triaxial stress distribution and major principal stress values at the failure was assessed to be 
negligible. In all numerical models with varying deformability properties of Poisson's ratio and the modulus of elasticity, the major principal stress values were similar and its deviation from the uniaxial tensile strength was lower than $4 \%$. Therefore, different materials with a same strength value were found to be able to give practically same failure loads and strength test results calculated in accordance with Eq. (1) which is suggested for determination of uniaxial tensile strengths of the drilled disc specimens.

It is well estimated that the deformability properties of 2 and 28 days cured rocklike cementitious mixes are significantly different. Also, the results of experimental study confirmed that Eq. (1) is usable for specimens with different deformability properties. As the drilled and casted specimens had same results, the drilling process was determined to cause no unwanted damage in preparation of the disc specimens. Therefore, it was assessed that the drilling process can be carried out to prepare specimens. For prevention of damaging during the specimen preparation, the drilling process should be done carefully and proper equipments like drilling tools should be used.

\section{References}

[1] Komurlu, E., Kesimal, A., Demir, A. D. "Dog bone shaped specimen testing method to evaluate tensile strength of rock materials", Geomechanics and Engineering, 12(6), pp. 883-898, 2017.

https://doi.org/10.12989/gae.2017.12.6.883

[2] Zhang, S., Lu, Y. "Experimental and numerical investigation on the dumbbell-shaped specimen of concrete-like materials under tension", Latin American Journal of Solids and Structures, 15(6), Article number: e93, 2018.

https://doi.org/10.1590/1679-78254632

[3] Tufekci, K., Demirdag, S., Sengun, N., Altindag, R., Akbay, D. "A new design test apparatus for determining direct tensile strength of rocks", In: Ulusay, R., Aydan, O., Gerçek, H., Hindistan, M. A., Tuncay, E. (eds.) Rock Mechanics and Rock Engineering: From the Past to the Future, Taylor \& Francis Group, London, UK, 2016, pp. 295-300.

[4] Fuenkajorn, K., Klanphumeesri, S. "Laboratory Determination of Direct Tensile Strength and Deformability of Intact Rocks", Geotechnical Testing Journal, 34(1), pp. 97-102, 2011. https://doi.org/10.1520/GTJ103134

[5] Li, D., Wong, L. N. Y. "The Brazilian Disc Test for Rock Mechanics Applications: Review and New Insights", Rock Mechanics and Rock Engineering, 46(2), pp. 269-287, 2013. https://doi.org/10.1007/s00603-012-0257-7

[6] Komurlu, E., Kesimal, A., Demir, S. "Experimental and numerical study on determination of indirect (splitting) tensile strength of rocks under various load apparatus", Canadian Geotechnical Journal, 53(2), pp. 360-372, 2016. https://doi.org/10.1139/cgj-2014-0356
The drilled discs are also used in a modified Brazilian test, which is an indirect tensile strength test method called as ring test [33-35]. In the ring test, the procedure is same with that in the standard Brazilian test. Only, the difference is using ring shaped drilled discs. Instead of indirect test methods, this study has a new suggestion to use drilled discs in direct tensile strength tests by using a new loading apparatus.

\section{Conclusions}

In conclusion, a new testing method of drilled disc tension (DDT) was assessed to be able to contribute much to the rock testing area by supplying ideal failure under the control of uniaxial tensile stress condition and eliminating the use of adhesives that can cause invalid failure problems in direct tensile strength (DTS) determination. According to the results obtained from this study, new researches on the DDT test are suggested to further for improving the method to be a popular way to determine DTS values of rock materials.

[7] Briševac, Z., Kujundžić, T., Čajić, S. "Current Cognition of Rock Tensile Strength Testing By Brazilian Test", The Mining-GeologyPetroleum Engineering Bulletin, 30(2), pp. 101-128, 2015.

https://doi.org/10.17794/rgn.2015.2.2

[8] Kourkoulis, S. K., Markides, C. F., Hemsley, J. A. "Frictional stresses at the disc-jaw interface during the standardized execution of the Brazilian disc test", Acta Mechanica, 224(2), pp. 255-268, 2013. https://doi.org/10.1007/s00707-012-0756-3

[9] Chen, R., Stimpson, B. "Interpretation of indirect tensile strength when moduli of deformation in compression and in tension are different", Rock Mechanics and Rock Engineering, 26(2), pp. 183189, 1993. https://doi.org/10.1007/BF01023622

[10] Erarslan, N., Williams, D. J. "Experimental, numerical and analytical studies on tensile strength of rocks", International Journal of Rock Mechanics and Mining Sciences, 49, pp. 21-30, 2012. https://doi.org/10.1016/j.ijrmms.2011.11.007

[11] Fairhurst, C. "On the validity of the 'Brazilian' test for brittle materials", International Journal of Rock Mechanics and Mining Science \& Geomechanics Abstracts, 1(4), pp. 535-546, 1964. https://doi.org/10.1016/0148-9062(64)90060-9

[12] Komurlu, E., Kesimal, A. "Evaluation of Indirect Tensile Strength of Rocks Using Different Types of Jaws", Rock Mechanics and Rock Engineering, 48(4), pp. 1723-1730, 2015. https://doi.org/10.1007/s00603-014-0644-3

[13] Komurlu, E., Kesimal, A., Demir, S. "Experimental and numerical analyses on determination of indirect (splitting) tensile strength of cemented paste backfill materials under different loading apparatus", Geomechanics and Engineering, 10(6), pp. 775-791. 2016. https://doi.org/10.12989/gae.2016.10.6.775 
[14] Markides, C. F., Kourkoulis, S. K. "Naturally Accepted Boundary Conditions for the Brazilian Disc Test and the Corresponding Stress Field", Rock Mechanics and Rock Engineering, 46(5), pp. 959-980, 2013.

https://doi.org/10.1007/s00603-012-0351-x

[15] Markides, C. F., Kourkoulis, S. K. "The influence of jaw's curvature on the results of the Brazilian disc test", Journal of Rock Mechanics and Geotechnical Engineering, 8(2), pp. 127-146, 2016. https://doi.org/10.1016/j.jrmge.2015.09.008

[16] Erarslan, N., Liang, Z. Z., Williams D. J. "Experimental and Numerical Studies on Determination of Indirect Tensile Strength of Rocks", Rock Mechanics and Rock Engineering, 45(5), pp. 739751, 2012. https://doi.org/10.1007/s00603-011-0205-y

[17] Mikl-Resch, M. J., Antretter, T., Gimpel, M., Kargl, H., Pittino, G., Tichy, R., Ecker, W., Galler, R. "Numerical calibration of a yield limit function for rock materials by means of the Brazilian test and the uniaxial compression test", International Journal of Rock Mechanics and Mining Sciences, 74, pp. 24-29, 2015. https://doi.org/10.1016/j.ijrmms.2014.12.001

[18] Yu, Y., Yin, J., Zhong, Z. "Shape effects in the Brazilian tensile strength test and a 3D FEM correction", International Journal of Rock Mechanics and Mining Sciences, 43(4), pp. 623-627, 2006. https://doi.org/10.1016/j.ijrmms.2005.09.005

[19] Ulusay, R., Hudson, J. A. (eds.) "The Complete ISRM Suggested Methods for Rock Characterization, Testing and Monitoring: 19742006", International Society For Rock Mechanics (ISRM), Ankara, Turkey, 2007.

[20] Willam, K. J., Warnke, E. P. "Constitutive model for the triaxial behaviour of concrete", IABSE, Bergamo, Italy, Rep. 19, 1974.

[21] Kohnke, P. (ed.) "ANSYS Mechanical APDL Theory Reference", Ansys Inc., Canonsburg, PA, USA, 2013.

[22] Unlu, T., Yilmaz, O. "Development of a New Push-Pull Direct Tensile Strength Testing Apparatus (PPTA)", Geotechnical Testing Journal, 37(1), pp. 60-70, 2014. https://doi.org/10.1520/GTJ20130040

[23] Komurlu, E., Kesimal, A., Durmus Demir, A. "A Numerical Study for Determining Ideal Size and Geometry of Dog bone shaped direct tensile strength test specimens", In: European Rock Mechanics Symposium 2016 (EUROCK 2016), Cappadocia, Turkey, 2016, pp. $325-330$.

[24] Demirdag, S., Tufekci, K., Sengun, N., Efe, T., Altindag, R. "Determination of the Direct Tensile Strength of Granite Rock by Using a New Dumbbell Shape and its Relationship with Brazilian Tensile Strength", IOP Conference Series: Earth and Environmental Science, 221, Article number: 012094, 2019.

https://doi.org/10.1088/1755-1315/221/1/012094
[25] Komurlu, E., Demir, S. "Drilled Core Specimen Testing Method for Determination of Tensile Strength Values of Rock Materials", Periodica Polytechnica Civil Engineering, 63(1), pp. 18-24, 2019. https://doi.org/10.3311/PPci.12524

[26] Tan, Y., Huang, D., Zhang, Z. "Rock Mechanical Property Influenced by Inhomogeneity", Advances in Materials Science and Engineering, 2012, Article ID: 418729, 2012. https://doi.org/10.1155/2012/418729

[27] Huang, H., Fan, P., Li, J., Wang, M., Rong, X. "A Theoretical Explanation for Rock Core Disking in Triaxial Unloading Test by Considering Local Tensile Stress", Acta Geophysica, 64(5), pp. 1430-1445, 2016.

https://doi.org/10.1515/acgeo-2016-0068

[28] Perras, M. A., Diederichs, M. S. "A Review of the Tensile Strength of Rock: Concepts and Testing", Geotechnical and Geological Engineering, 32(2), pp. 525-546, 2014. https://doi.org/10.1007/s10706-014-9732-0

[29] Bineshian, H., Ghazvinian, A., Bineshian, Z. "Comprehensive compressive-tensile strength criterion for intact rock", Journal of Rock Mechanics and Geotechnical Engineering, 4(2), pp. 140-148, 2012. https://doi.org/10.3724/SP.J.1235.2012.00140

[30] You, M. "Strength criterion for rocks under compressive-tensile stresses and its application", Journal of Rock Mechanics and Geotechnical Engineering, 7(4), pp. 434-439, 2015. https://doi.org/10.1016/j.jrmge.2015.05.002

[31] Coviello, A., Lagioia, R., Nova R. "On the Measurement of the Tensile Strength of Soft Rocks", Rock Mechanics and Rock Engineering, 38(4), pp. 251-273, 2005. https://doi.org/10.1007/s00603-005-0054-7

[32] You, M. "Strength criterion for rocks under compressive-tensile stresses and its application", Journal of Rock Mechanics and Geotechnical Engineering, 7(4), pp. 434-439, 2015. https://doi.org/10.1016/j.jrmge.2015.05.002

[33] Chen, C., Hsu, S. "Measurement of Indirect Tensile Strength of Anisotropic Rocks by the Ring Test", Rock Mechanics and Rock Engineering, 34(4), pp. 293-321, 2001. https://doi.org/10.1007/s006030170003

[34] Li, X., Wu, Q., Tao, M., Weng, L., Dong, L., Zou, Y. "Dynamic Brazilian Splitting Test of Ring-Shaped Specimens with Different Hole Diameters", Rock Mechanics and Rock Engineering, 49(10), pp. 4143-4151, 2016. https://doi.org/10.1007/s00603-016-0995-z

[35] Sarfarazi, V., Schubert, W. "Numerical Simulation of Tensile Failure of Concrete in Direct, Flexural, Double Punch Tensile and Ring Tests", Periodica Polytechnica Civil Engineering, 61(2), pp. 176183, 2017.

https://doi.org/10.3311/PPci.9028 